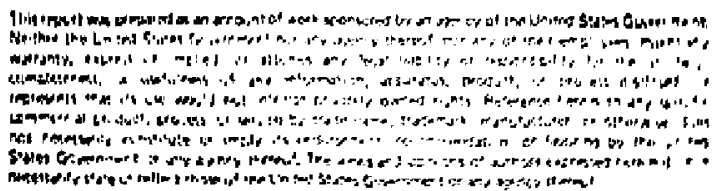

BLAC-PUB-2930

June 1982

$(T / E)$

TRE TRTTOA AS A THREE-NUCLEOIJ-OAB-MESON PROBLEA

H. Fierre Noyes and lartus $x$, Orlowsk Stanford Linear Accelerstor center stanford Unfverstty, stanford, Californin 94305

\title{
ABstrict
}

The standard method for basing nuclear physied on elenentary particle phyates is to first derive a "potential" and chon ure this interaction in the nourelactolstic Schrosdinger equation for the musleonic dogrees of freedow, Onfortunately there has never been a consangas as to hov to perform the first step. Currently we have dispersion-thaoretic nodels and ona-bosou-exchange models which contaln much the onde physies, but which differ In detall: more "modero" approaches starc from quatk bags, but agatn there is no consensus as to whether the bas should be large or smal1. In this paper we offer an alternative appreash in which the wesonic and nucleonic degrees of Freeiom are put on the game footing.

The boafc relativistic three particle Fadtauv equationg for separable two particla abplitudes were given long ago by Lovelaca, and more recently by Brayshaw. Windesay has show thet 12 we opectalizo tho input to a two particle amplitude containing only the term gendrated by two particles $m_{f}$, in forming a bound state of mass $H_{1 j}$ - a ralntivintic generalication of the satforing langth mode? - that the ragulting Intogral equations can be essily solved numerically and give unitary and covariunt reaulta. In particular they reproduce the logartehmic accumuletton of nonrolativisti: three particle bound states predicted by Ef iwov when the sadtertiog length goes to infinity. T.F this mode? Is gtill Lurther spectalized by essuming the systent to consigt of two scalah parcicles of mass $\mathrm{m}_{1}$ and $\mathrm{m}_{2}$ and 2 meson of mask $m_{0}$ with no scattering between the porticles and bound atate of wass $\mu_{10} \equiv m_{f}$ physically indistingutshable from the particles which never cowe apant (i,e., there is no m $m_{10}$ seattering for phyotical vomenta) except at short distance, one can calculâte a fully covertamt and unitery off-shell anplitude for the scattering of $\mathrm{m}_{1}$ and $\mathrm{m}_{2}$ caused by repauted exchanges of qe

At this point te conld simply use the arplitude so generated in a three nucleon Faddecv equarion, or use it to compute a "potential" from the Low equation. We think a wre interesting alternactvi is to volte down and solve the Faddeev-Yakubovsky four particka equitions - which have been derived for this type of "zero range" theory - Ior a systan coutaining $m_{1} m_{2} m_{3}$ and $m_{0}$. Then our restrictions reduce the $12(3,1)$ configurations to slx anplitudes and eliminate the $(2,2)$ configurations entirely. Thus the difference of including the mesonic degree of froedom is that chere are six rather than three anplitudes and that the aquations have internet1y a four particle rather than a three particle propagaeor. Expl lelt equations will be given.

- Work supported by the Department of Energy, contrace JIE-AC03-76sFo0515.

(Prenented at the International Conforance on Nucloar seructure, Ambterdam, August 30-5eptember 3, 1982.) 


\section{DEa2 018606}

The baste assumptions on which our three and four body covartant theory of stngte mecon exchenge rest are that the only elementary process

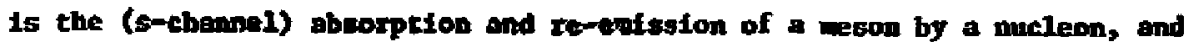
that there is no direct nueleow-nusleon scactertng. This is a covartant generalization of the scactering Iengti, or zero range "bound state," sodel

of nonrelativisese quancum mechanics $\left(1, e ., c^{16} \sin \delta / q=(-1 / a-1 q)^{-1}, a>0\right)$. We use $1, j, k, \ldots$ to digtinguith nucleons and $Q$ to distingulsh the meson; generalizntion of the nodal in betefly discussed at fine end of the paper. For siuplteicy to confine ourentvos here to seatar nucleons and sealar wescas, folloring an old cradtelon of attempts to understand nuclear forceg in a covariant contaxt; agan, brief difcussion of the removal of this rezeriction wt11 Eo11ow.

Once a separable, untery and covertant two particle amplitude is postulated, Faddeev equation for the relacivistic three particle probjan follow and predict untery, covarinnt, and time reversal invariant three particle amplitudes, as has been provod several times,1,2,3 Aithough we restrict ourbelves nest to two or throe nucleons and one meson, subseguest work wil telax both restrfetions, and include degrees of freedom corresponding to antipartieles. Our restriction at each level of approximation to a finite mming of particulate degrees of freedom and exact unitarity differentiates our approech froen the 5 matrix progra: in a subtle vay. 5-matricfats who follor ches add to unltarity the postulace of "erossing" wich necessarily brings in an infinite muher of degrees of freedom as customatily employed. We clearly differ from theories based on the second quantiataton of the nater fleld, whic bring in an infinite nubber of degreds of freadotn in another way. What has recently been discovered ${ }^{4}$ is

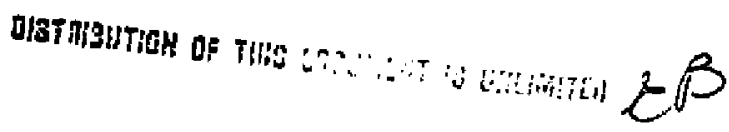


that by concentrating on two vaticle acatering as the basic concept in can go to a noncelativiste limit correapending to "two bndy interactions" In a llamilonian theory without wiguity, but need not take that liwit; our theory is both covertant and unitary at any energy.

The couartant three particle model explored by Lindesay ${ }^{3}$ is extremely simple. He simply cake the Imvarfant two perticle anplitudes in the space of three particles of woss $m_{a}, q_{b}$ and $m_{f}$ represented in the coordinate syster in which $k_{a}+k_{b}+k_{c}=0$ and the Invariant four-momantum $H=E_{a}+c_{b}+c_{c}$ to be

$$
t_{a b} \equiv t_{c}\left(k_{c}, k_{c}^{\prime} ; H\right)-\sqrt{a_{a b}}(2 \pi)^{-2} c_{c} d^{3}\left(k_{c}-k_{c}^{\top}\right) D_{a b}^{-1}\left(a_{a b}\right)
$$

where

$$
\left.D_{a b}(a)+{ }^{2}{ }_{1 b}\left({ }_{a b}\right)\right]^{1 /}-\left[-q^{2}(a)\right]^{1 / z}
$$

and

$$
q_{a b}^{2}(s)=\left[s-\left(m_{a}+m_{b}\right)^{2}\right]\left|s-\left(m_{a}-m_{b}\right)^{2}\right| / 49
$$

with

$$
c_{a}=c_{m_{a}}\left(k_{a} ;=\left(m_{a}^{2}+k_{a}^{2}\right)^{3} .\right.
$$

In this wodel we see that the entre dynamica 18 specified by the "bound state mage" $\left.\right|_{a b}$ where the two particle amplitcude has an "s-channel pole." Since $s_{a b}$ is tho tinvarlant four momentum squared of the ab pat", the requirement that the two particlu sataturing be unaffected by the "spectator" a In our baste description (the "cluster property") tells us that 1.2 conrdinate gyntom where $a_{a b}=\eta_{a b}^{2}+v_{a b}^{2}$ (the ab zero monentum system), the momentum of the spectator $k_{c}^{a b}$ ranges from zero to infinity. raking a lorentz transformation of these linits rn the three particle zero 
momentum system, wo find chac $k_{e}$ lies between aero and $\left(H^{2}-m_{c}^{2}\right) / 2 H$. We cuphasize this point since it is not alvers miaratood that the asyuptotic variables In a relativistic threo particle problem are bounded once $\mathrm{M}$ is flked, and hence in a separable model lead to ftutte Integral equations. Given that the two particle iaput is unicary, as holda for chis model, the form of these equations guarantees the unitarity of the threa particle anplitudes computed from then, as was proved by Freedinan, Lovelace and Namyslowsk 1, by Brayahas' and again by Lindesay."

For the two nueleen one geson modet we first consider, we call the nucleons $m_{1}$ and $m_{2}$ and the megon $m_{Q}$, and make two postulates; (a) there is no elementary nueken-nucleon scatering $\left(1, \ldots, t_{12} \equiv t_{q}=0\right)$ and (b) that the bound state mass $\mu_{1 Q} \equiv m_{1}$ and is asymptotieally indistinguishable phygically trom the particle $m_{1}$. The equation then describe a model for single particle exchange and production which is still coveriant and unitary, as han bean claimed provtounly.4,5 For the current spipilcation to nuclear phyoies wo opecialize the nodel still further by postulating (c) that the megon never appears as a Iree asympcotic particle. That we can achteve "confimant" In chia souge without dastoyting covarinnce or mitarity may not be lanedicty zrious, so we will spell out the gteps wtth gome care.

Our first step, In the two-nucleon, one meson space, is to note that inder posculaces (a) and (b) we brwe only two input applitudes $t_{19} \doteq_{j}$ with $1, j \in 1,2$ and that in the three particle zero nomentio system $s_{1 Q}=\left(\varepsilon_{i}+c_{Q}\right)^{2}-\left(k_{1}+k_{j}\right)^{2}=\left(g-c_{j}\right)^{2}-k_{j}^{2}-x^{2}+m_{j}^{2}-21 c_{j}$. Further, if we start with a spnelator $n_{j}$ with ament $\mathrm{k}_{j}^{(0)}$ the "bound state" (with mass $\left.u_{1 q}=m_{i}\right)$ has coment $\cdots-j, j=c_{i}^{(0)}+c_{i}^{(0)}$. Thus if we 
rationalize the denominator In $\mathrm{Eq}$. (I) and define $t_{\mathrm{j}}=\mathrm{c}_{\mathrm{g}} \delta^{3} \tau_{\mathrm{f}}$ we find that

$$
\tau_{j}\left(k_{j}, k_{j}^{(0)} ; W\right)=-\frac{r_{l}^{2}}{2 M\left(\varepsilon_{j}-E_{j}^{(0)}\right)}+\hat{\tau}_{j}=-\frac{r_{1}^{2}}{2 M} p_{j}\left(k_{j}, k_{j}^{(0)}\right)+\tau_{j}
$$

where $\hat{t}_{j}$ containg the branch cut in $s_{10}$ starting dt $m_{1}+m_{Q}$ which in the two particle space describee meson-nuclion scattering. Wich these tiftial condtions all we need do to prevent meson production 16 to define $H_{1 j}=t_{1} \delta_{1 j}+\tau_{1} z_{1 j} \tau_{j}$, Iterate the covartant Faddzev equations once to obtain an equation for $z_{1 \mathrm{j}}$, and cake $\hat{i}=0$ closing the production channel. For reasons we discuss below, the physical amplitudes for $\mathrm{m}_{1}+\mathrm{w}_{2}$ scattering are not $z_{i j}$ but $\Gamma_{i} z_{1 j} \Gamma_{j} \equiv K_{i j}$. Following the above procedure we find that they artisfy the coupled equations

$$
\begin{aligned}
& k_{1 j}\left(\underline{k}_{1}, k_{j}^{j} ; M\right)+\bar{\delta}_{1 j} \Gamma_{f} R\left(\underline{k}_{f}, k_{j}^{q} ; M\right) \Gamma_{j} \\
& \left(M^{2}-m^{2}\right) / 2 M \\
& =\frac{1}{2 M} \int_{0}^{m_{k}} \frac{d^{3} k_{k}^{\prime \prime}}{c_{k}^{\prime \prime}} \bar{\delta}_{i k} r_{1} R\left(\underline{k}_{1}, k_{k}^{\prime \prime} ; M\right) r_{k} P_{k}\left(k_{k}^{\prime \prime}, k_{k}^{\prime}\right) k_{k j}\left(k_{k}^{\prime \prime}, k_{j}^{\prime} ; M\right) \\
& \left.=\frac{1}{2 H} \int_{0}^{\left(M^{2}-m_{k}^{2}\right) / 2 M} \frac{d^{3} k_{k}^{\prime \prime}}{E_{k}^{f f}} k_{1 k}+k_{i}+k_{k}^{\prime \prime} ; M\right) P_{k}\left(k_{k}+k_{k}^{\prime \prime}\right) \Gamma_{k} R\left(k_{k}^{\prime \prime}, k_{j}^{\prime} ; M\right) \Gamma_{j} \bar{\delta}_{k j}
\end{aligned}
$$

where

$$
R^{-1}\left(k_{j}, k_{j} ; M\right)=\varepsilon_{i j}\left(\varepsilon_{1 j}+\varepsilon_{i}+\varepsilon_{j}\right) ; \bar{\delta}_{i j}=1-\delta_{i j}
$$

and

$$
E_{1 j}=\left[m_{q}^{2}+\left(\underline{k}_{I}+\underline{k}_{j}\right)^{2}\right]^{k}
$$

We see lumediately that these are covariant coupled channel equations of the Lippmann-Schwinger type and hence define unitary amplitudes. Further, 
the unitarity is tadependent of the (finite) value of $r_{1} r_{2}$, a point which we exploit belon.

In order to understand thy the regidue at the pole which, if we start trom Eq. (1), would appear to be fixed by two particle unitarity can be treated ag an arbitrary parameter in our context, it is convenient to igolste the prinary singularities by using Eq. (5), whlch gives

$$
M_{1 j}=\tau_{1} \delta_{1 j}+\left(\frac{r_{1}^{2}}{s_{10}-m_{j}^{2}}+\tau_{1}\right) z_{1 j}\left(\frac{r_{j}^{2}}{s_{1 Q}-m_{j}^{2}}+\hat{\tau}_{j}\right)
$$

and compare this with the relation between the Faddeev amplitudes and the physical applitudes whose squares ore related to cross nections as given by Osborn and Bollé, Eq. (IV.7), which in our notation 16

$$
\begin{aligned}
M_{1 j}= & c_{1} s_{1 j}+F_{1 j}+G_{1 j} \phi_{j}\left(s_{1 Q}-m_{j}^{2}\right)^{-1}+\phi_{1}\left(s_{1 Q}-m_{1}^{2}\right)^{-1} \tilde{G}_{1 j} \\
& +o_{1}\left(s_{1 Q}-\sigma_{1}^{2}\right) k_{1 j}\left(s_{1 Q}-m_{j}^{2}\right) o_{j} .
\end{aligned}
$$

This shows us that if the bound state wave functions $\phi_{1}$ arc identified, as they should be in our s-channel (or zero range, or on shell) model, with the asymptotic normalization of the bound state $\Gamma_{1}$, the 3-3 amplitude is $F_{i j}=\hat{i}_{i} z_{i j} \hat{T}_{j}$, the amplitude from which breakup $=3$ be computed (cf. OB $E_{\text {q. }}\left(I_{.2 j}\right) G_{i j}=\tilde{\tau}_{i} z_{i j} \Gamma_{j}$, the amplttude from which coalesence can be computed $\hat{i}_{i j}=r_{1} z_{1 j} \hat{t}_{j}$, and the elastic scattering and rearrangement amplitudes are given by $K_{i j}=I_{I} Z_{I j} I_{i}$, as asserted without pronf above. But then we see chat indeed if we take $\hat{t}=0$, the only scattering processes are elastic and rearrangement scattering. As is well know in nuclear physics, the asymptotic normalization of the bound state wave function, or "reduced width," need not correspond to what we would compute from a 
gero rango theory, Thus in a sense $1 t$ is tande 1 dapandent, but in fact 1t can he deteminod by expariments which break up a two particle bound state and shown to be indupendent of the particle used for thu brarkup. Thua, so long an wo confine our theory to the egion below meson productiop threchold, as 18 appropriate for our discussion of nuclest phystes, we con treat this parmater as ewpirical without interfering with the flux conservation of the nucleonic degrees of freedom. A tiatlar freadea was used by Nado in his "nonrelativistic field theory" for n-d acattering? In which he trents the raldue at the mpd vertex os an adjustoble parameter. We return to the consideration of this constant as measuring how much of the nucleon is "composite" an' how mueh "elententery" in our final discugaion.

Our final stap at the two nucleon, one meson laval is to note that aince $k_{1}=-k_{j}$ In elther the initial or the Einal state, and our postulate (c) doet not allow us to distinguish the "bound stata" w from the "bare ducleon" $a_{1}$, we anly have ane amplitude $T_{12}\left(\underline{k}, \underline{k}^{*}, 10=k_{11}\left(k, k^{\prime}, 4\right)+\right.$ $K_{21}\left(-k_{0} \underline{k}^{\prime}\right)=k_{12}\left(k_{0}, \underline{k}^{\prime} i M\right)+k_{22}\left(-\underline{k},-\underline{k}^{+} ; H\right)$ where we hav taken as our noferened direction the direction of the momencul $k^{\prime}$ particle 1 in the inttial gtate, and the equality of the two forms expreased timi reversed Invartance, as xtaranteed by the equivalence of the two forths of to. (6). To relatu un theory ta more tarillar modes we mole that with the arbitrary 1 aramear $g_{1} \varepsilon_{2}$ replacing $\bar{i}_{1} \Gamma_{2}$ the equations do indeed reduce In the nonrolutwatid kfnematis regien (where $M=t_{1}+t_{2}$ ) to the Lippmann-Sehwinger equation of scatter:st, by a Yukawn potential wincu $r_{2} \Gamma_{2} R\left(\underline{k}, \underline{k}^{\prime} ; M\right)-g_{1} b_{2}\left[r_{Q}^{2}+\left(\underline{k}-\underline{k}^{\prime}\right)^{2}\right]^{-1}$ and $P_{k}$ goes to thu ugual nonrelativistic propagatol. Dut of course we need not take this 1 Imlt. The $T_{12}$ we have obtelned to tully covarianc off shell two partcile amplitude 
wh .ch can bo wad, for axnmple, in covartant three perclcle Faddeey equations, or thote nonroleclviste limit.

We bellove the abov: ruggated use of the ajplitude we have obtalned Is a becter way to do nuclest phystcs that using a "potential" for the n,n,p sygtem, but atil we have shom how to Include Covlowa effecta in this covariant dofexiption, the construction of the corcesponding potontial I11 have tes Importance. This can easily be accouplished, glace we aboud long ago that the tor equation cen be csed as a defining equation given a half off sholl wo particle aplitude consistent with the revered invartance. Explictily for the case at hand the nonrelativistle energy parameter $z=M-m_{1}=m_{2}$, and we can write

$$
\begin{aligned}
v\left(k, k^{\prime}\right) & =\tau\left(k, k^{\prime} ; m_{1}+z_{2}+z\right) \\
& -\oiint_{0}^{\infty} q^{2} d q \frac{T\left(k, q ; m_{1}+m_{2}+\tilde{q}^{2}\right) T^{*}\left(q_{1}, k^{\prime} ; m_{1}+m_{2}+q^{2}\right)}{q^{2}-z}
\end{aligned}
$$

whert we have for afmplifity confined ourselves to s-uaves and the $\boldsymbol{\Sigma}$ superimposed on the integral fs supposed to renind us to Include any $m_{1} m_{2}$ bound states predicted by the todel in our calculation. Sir the z-dependence of the right hand alde is not necessarily negligibl (except for high energy where we go to the Bom approxikation), chis cal sulat tes wil tell us to what acturacy and over shat energy range nur modes can Indered be reprenented by il static potential.

Annther npplifution of our apprnaci looks incerestfag. Inetead of using relaclviato Foddec equations and $\mathrm{T}_{1 j}$ computed from the two nueleon one meson ayntem to enlculate the thref aucleon system, we can formulato relat dviate inur particle Fadduev-Yukubuvsiky equations for threa nucloons 


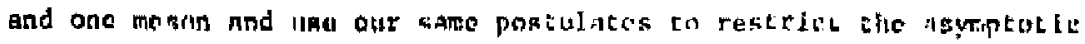
degrees of froadom to the three nucleons. The zero rathe nanrelativisite equationg uru engy to dorlve and the genctallzat lon of thesu to nepartible relativiste wo partele driving tarms is equally stralght forward. For our spectal model the fact that we allow no elemencary particlo-particle scattering Intodiately alminates the $(2,2)$ configuritlons. Nortally there are $4 \times 3=12(3,1)$ eonifgurations, but since $Q$ ts noe allowed to be a spectator otther of thit chree particle systems or within the subsystems, this reducen the number of amplicudes to $3 \times 2=6$. We symbolize theae by ${ }_{f}$ where the superscrtpt i labels the spectator of the two nutlem ont meson subsyatom and the ubborigt $\mathrm{f}$ labels the spectator fn that subsystem. Stnce $\mathrm{J} f \mathrm{f}$, tho IncIuaton symbol of the Faddeev-iakubovgliy hiorarchy 10 can in out ones attlply bo toplaced by a $\bar{F}_{i f}$, and our four paresclu amplitudes with $1,1, k, 2, m<1,2,3$ satisfy the six coupled equations

$$
\begin{aligned}
& \boldsymbol{F}_{j}^{\ddagger}\left(k_{1}, \underline{k}_{j} ; M_{4}\right)+\mu_{j j}^{(j)}\left(\underline{k}_{j}, \underline{k}_{j}^{(0)} i M_{j}^{(j)}\right)=-\sum_{k} \bar{\delta}_{i k} \sum_{k} \bar{\delta}_{i m} \sum_{k} \bar{\delta}_{k k} \\
& \times \int_{0}^{\left(m_{4}^{2}-m_{k}^{2}\right) / 2 M} \frac{d^{3} k_{k}}{c_{k}} \int_{0}^{\left(m_{j}^{(0)^{2}}-m_{2}^{2}\right) / 2 H} \frac{d^{3} k_{l}}{E_{l}} M_{j m}^{(i)}\left(k_{j}, k_{k} ; M_{i}^{(3)}\right) \\
& \times z_{m 2}^{i k} F^{k}\left(k_{k} \cdot k_{i} ; M_{4}\right)
\end{aligned}
$$

where

$$
M_{3}^{(1)}\left(k_{1}, H_{4}\right)=M_{4}^{2}+m_{1}^{2}-2 H_{4} c_{1}
$$

and 


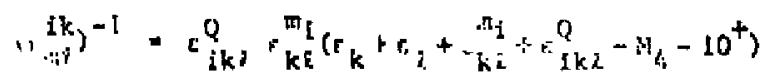

$$
\begin{aligned}
& E_{i k,}^{Q}=\left[m_{Q}^{2}+\left(k_{i}+k_{k}+k_{i}\right)^{2}\right]^{{ }^{2} \varepsilon} \\
& c_{k i}^{m_{1}}=\left[m_{1}^{2}+\left(\underline{k}_{k}+\underline{k}_{i}\right)^{2}\right]^{2} \text {. }
\end{aligned}
$$

In contrast, If we du not incluba the mesonic degree of fruedom in the internal dynamics, we w11 have only shree coupled equations for the chree faddeev components ${ }^{(3)} \mathrm{F}_{i}\left(h_{i}, \mathrm{q}_{1} ; M\right)$ given by the three couplad equations

$$
\begin{aligned}
& { }^{(3)} F_{i}\left(k_{1}+q_{i} ; M\right)+T_{1}\left(q_{i}+q_{i}^{(0)} ; H\right) \delta_{i} \delta_{0}^{3}\left(k_{i}-k_{l_{0}}^{(0)}\right) \\
& -\sum_{j} \bar{x}_{i j} \int_{0}^{\left(M^{2}-m_{j}^{2}\right) / 2 m_{j}} \frac{J^{j_{k}} j}{\mathrm{c}_{j}} \int \frac{d^{3} q_{j}}{\mathrm{c}_{j}} \tau_{j}\left(q_{1}, \bar{g}_{1}, M\right) \\
& \times s^{3}\left(\bar{q}_{1}+\underline{k}_{1}+\underline{k}_{j}\right) R_{1 j}\left(\underline{k}_{1}+q_{j} ; M\right) F_{j}\left(k_{j}, q_{j} ; M\right)
\end{aligned}
$$

where

$$
\begin{aligned}
& {\mathbf{E}_{i j}^{-1}}^{-1}=\varepsilon_{i j}\left(\varepsilon_{i j}+\varepsilon_{i}+c_{j}\right) \\
& \varepsilon_{i j}=\left[m_{k}^{2}+\left(k_{i}+k_{j j}\right)^{2}\right]^{\frac{k}{k}} \\
& \varepsilon_{i}=\left(m_{i}^{2}+k_{i}^{2}\right)^{\frac{1}{2}} \\
& E_{j}=\left(m_{j}^{2}+k_{j}^{2}\right)^{\frac{1}{2}}
\end{aligned}
$$

Since we have sect above that $T_{i} \equiv T_{j k}=H_{j j}+M_{j k}$, the Faddeuv equation can be derfved from the four parejcle equation by forming ${ }^{(3)} F_{1}-F_{j}^{1}+F_{k}^{1}$ where the approxitratim will he good so long as the signifleant momenta in the equations ore all small crmpared to $\mathrm{m}_{\mathrm{c}}$. Quantitativo investigation of this approximat fon will chen reveal to what extent the ugual nuclear 
phyates opproximation ts valdd, and where the internal dynanice ("three bady foree" and modffication of the two body off shell effecte) becomes Important in the three nucleon problem in the one meson exchango approximation.

We anticlpate that to the extent that a one meson exchange model tives a reasonuble description of nucleon-nucleon scattering, these mesonic effacte will be small at low energy. But this does not mean that thuy are phyelcally unimportant for nuclear phys lcs. For an adequate cest of this question wo most 80 beyond the one meson exchange approximation and formulate the nocleon-nucleon problem Itself as a two-nucled tro-meson syaten waing Faddeev-Yakubovsky equations. To be reslistic wo wet of course use pseudoscalax pien and also include $n-\pi$ scattering fand the aucloon-antinucleon channels. In th1s way we might hope to unify the one-bosen axchange models and the dispersion-theoretic models, providad our description of $\pi \pi$ scattering produces the $\rho$ and we can couple in the w Phenomenologicnliy. Ac this point we must also face the problam mentioned above of precisely how our replecement of $\Gamma_{f} \Gamma_{j}$ by $B_{f} g_{j}$ treacs the meleon of partly comoogite and partly bare. The three nucleon problem then beconte e flve body problem, but juiging by the simplifications our adol led to in the case discussed in this paper, we can hope that this w11 atill prove cractible. Our conclusion is that this appronch could provide a syatematic way to Investigate mesonic degrees of frandom in nuclat In a gystemaric way using finite and controlled approximations et each step. 


\section{RETERENCES}

1. D. Z. Freednan, C. Lovelace and J. H. Namys lowski, Nuovo Cimento 43A. 258 (1966).

2. D. D. Brayshow, Phys. Rev, D 18, 2638 (1978).

3. J, Y. Zindumy, Ph.D. thesis, Stanford, 1981, avanable as staC Report No. 243.

4. H. Plerre Noyes and J. V. Lindesay, SiAC-PUB 2863 (1981).

5. H. Plerre Hoyes and J. V. Lindesay, "A Covarlant and Unitary Equation for Single Qunitur Exchange," subntted to Phys. Rev. Lett.

6. T. A. Odbom and D. Bollk, Phys. Dev. CB, 1198 (1973), hereinafter op.

7. R. Aaron, R. D. Amado and Y. Y. Ten, Phys. Rev. 140, B1291 (1965).

8. H. Plorte Noyes, Pros, in Nuci. Thys. 10, 335 (1968).

9. H. Plarro Noyes, "Zero Range Scattering Theory I. Nonralativisele Throe and Four Particle Equations," Phys. Rev. C (in preas).

10. O. A. Yakubovsky, Sov. J. Nuel. Phys. 5, 937 (1967). 